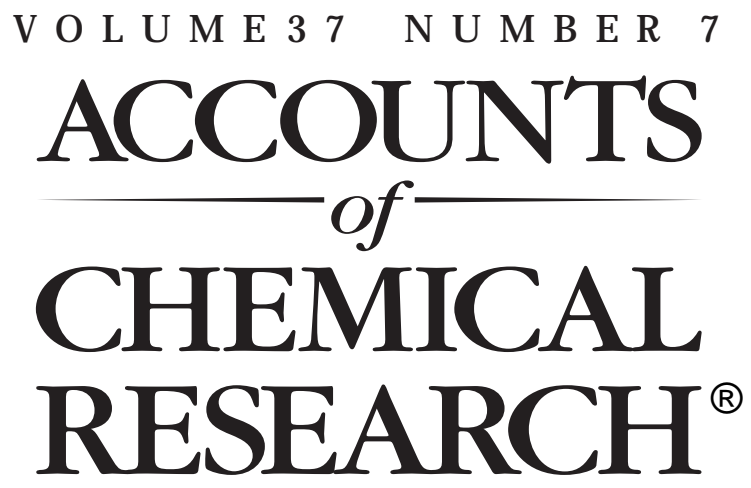

JULY 2004

Registered in U.S. Patent and Trademark Office; Copyright 2004 by the American Chemical Society

\title{
CORRESPONDENCE
}

\section{The Conversation Continues I}

\section{Dear Roald:}

I read with much interest your trialog ${ }^{1}$ in Accounts of Chemical Research. However, I believe that you and your coauthors are a bit young to have experienced, in real time, the sea change in the way organic chemists essentially abandoned resonance theory as their sole means for qualitatively rationalizing organic structures.

I remember in the 1940s how difficult Pauling's first edition of The Nature of the Chemical Bond was for organic chemists. They were delighted in the way the theory used ordinary structures, but it threw them for a loop trying to understand what resonance structures really meant. Wheland tried to ameliorate the situation with his 1941 book, The Theory of Resonance. Oddly, you and your colleagues clucked a bit over Hückel's thinking in terms of vibrating strings but failed to mention Wheland's corresponding use of coupled pendulums.

One of the positive things that came al ong about the same time as Pauling and resonance theory was to have more structure determinations and also more modern ways of printing chemical formulas. The result of these changes led to efforts by most organic chemists to draw structural formulas closer to their proper geometries than was done previously, and this made real sense for using resonance structures effectively.

Less positive for resonance theory were things such as cyclobutadiene. Cyclooctatetraene you could explain away as nonplanar, but not cyclobutadiene. In private conversation, Pauling maintained that cyclobutadiene should have resonance stabilization like benzene but, when pressed, suggested that the angle strain might be large enough to allow dissociation to two molecules of acetylene.

You may not be aware (published before you were born) that Pauling was quite familiar with MO theory and had a fine paper on application of the theory to aromatic substitution with Wheland. ${ }^{2}$ This makes me wonder why Pauling did not do cyclobutadiene by MO theory early on. Maybe he did and was surprised, or dismayed, by the discrepancy with the VB method.

Many organic chemists, particularly those more physically inclined, used resonance but longed for something more keyed into atomic orbitals that slowly began to be taught in physical chemistry. So when Coulson published his 1947 review article on molecular orbitals and Dewar came out with The Electronic Theory of Organic Chemistry, organic chemists perked up their antennae and began trying to sort out what these worthies were talking about. This was particularly hard for me, because I had never had a chemistry course where quantum mechanics was even mentioned. I remember discussing at great length at an evening seminar at MIT with Gardner Swain how to understand the way Coulsen formulated $\mathrm{O}_{2}$.

For me, as I described in some detail in my ACS biography The Right Place at the Right Time, the defining point was about 1950, when I thought I had conquered the qualitative ideas of Coulsen and Dewar. In consequence, I announced, in the very first lecture to my senior-level physical organic class, that I was going to not mention resonance henceforth but instead would explain the phenomena discussed in the course with my new-found knowledge of molecular orbitals. After this lecture, I realized that, while I could draw a great orbital diagram for the allyl cation, I had no way of locating the charges on the end carbons, which is so obvious from the resonance representation. Then, I thought about trimethylenemethane. I could see why it was not stable and not analogous to carbonate only by writing resonance structures.

The solutions to these problems for me came from William G. McMillan, a theorist from UCLA, fortunately teaching for a year at Harvard. I had known McMillan very well at UCLA where we did a lot of research together. I was the guy who got stuff from the stockroom and blew the glass for the equipment, while Bill explained what we were doing. Bill said at first, just read Eyring, Walter, and Kimble, but I said I need to know for my lecture next week. Further, I had already tried $E, W, \& K$ and found what I wanted therein was in a very late chapter. So finally, I got Bill to sit down with a pad of paper, where he admitted he was a bit rusty on the stuff but immediately used group theory (which I knew little about) to do the allyl cation with different symbols for $\alpha$ and $\beta$. I exclaimed, "You mean it is that easy!"

So, I was off to the races, and just then Andy Streitwieser was a postdoc, and he was pleased to be involved. So, we started calculating everything within reason we thought was interesting, preferably where we could use group theory, but we had nothing to do the numbers with but a Marchant calculator. This effort wound up in joint papers. ${ }^{3}$ Needless 
to say, I did finish my MIT class, holding to my promise to use MO theory to explain various physical organic phenomena.

At the time a few years later, when Andy and I published our respective books, ${ }^{4}$ there was enormous enthusiasm because, as I said earlier, there was a real hunger for a more physical basis than Pauling's resonance approach. Andy's book shortly became a champion in the Citation Index. My little, much less scholarly, book was widely used as a text and went through 16 printings. I gave week-long lecture series at several companies and spent about a month giving a MO course in Münich. Oddly, when we could provide access to IBM computers and let the students calculate properties by the extended Hückel theory, the interest of the class was much lower.

I believe resonance or VB, whatever you want to call it, began to lose ground because there was no easy way to make calculations, even on small molecules. The matrix elements were especially difficult; even my super-structural colleague at Caltech, Verner Schomaker, was not versed in Pauling's superposition diagrams. I wanted to try them but failed badly to make consistent sense out of the procedure, and of course, there are no zero elements in the matrices.

Then there was, as you mention, the unwillingness of Linus to continue to extend the theory further. Perhaps he was aware of the "Pauling point" too! Personally, I liked and still like the resonance approach, but I disliked the way Linus described it. If you think of $\pi$ systems, like benzene, as entities where interelectronic repulsions largely can be thought to determine the favorable locations for the $\pi$-electrons, you can pair those electrons across the $\sigma$-bonds one way or the other and it makes better qualitative sense of the resonance idea.

Verner Schomaker and I did quite a bit of work to try to make resonance structures more understandable (we hoped) as electron-pairing schemes. ${ }^{5}$ We were rather proud of the result, so we talked to Linus and I asked him if he agreed that this way of designating the interactions was indeed a better way to describe resonance. $\mathrm{H}$ is reply to me was typical Pauling, “Jack, you should know that I don't like to change anything in The Nature of the Chemical Bond."
While Andy and I did not contribute to basic MO theory, I believe we did play a significant role in getting organic chemists to embrace and use the Hückel theory.

Vlado Prelog introduced me once at a seminar at the ETH saying "I decided if Roberts could do Hückel theory, I could, too." A nice tribute!

With best wishes,

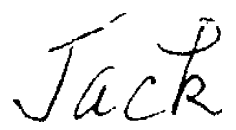

John D. Roberts

California Institute of Technology

\section{References}

(1) Hoffman, R.; Shaik, S.; Hiberty, P. C. A Conversation on VB vs MO Theory: A Never-Ending Rivalry? Acc. Chem. Res. 2003, 36 (10), 750-756.

(2) Pauling, L.; Wheland, G. W. A quantum-mechanical discussion of orientation of substituents in aromatic molecules. J. Am. Chem Soc. 1935, 57, 2086-2095.

(3) (a) Roberts, J. D.; Streitwieser, A.; Regan, C. M. Small-Ring Compounds. X. Molecular Orbital Calculations of Properties of Some Small-Ring Hydrocarbons and Free Radicals. J. Am. Chem. Soc. 1952, 74, 4579-4582. (b) Roberts, J. D.: Streitwieser, A. Quantum Mechanical Calculations of Orientation in Aromatic Substitution. J . Am. Chem. Soc. 1952, 74, 4723-4724.

(4) (a) Roberts, J. D. Molecular Orbital Calculations; W. A. Benjamin, Inc.: New York, 1961. (b) Streitweiser, A. J ., J r. Molecular Orbital Calculations for Organic Chemists; J ohn Wiley: New York, 1961.

(5) Roberts, J. D.; Caserio, M. C. Basic Principles of Organic Chemistry, 2nd ed.; W. A. Benjamin, Inc.: Menlo Park, CA, 1977; Chapter 21.

Received November 20, 2003

AR030293B 